\title{
A computer-aided decision supporting tool for nearly zero energy building renovation
}

\author{
S. Domjan, C. Arkar \& S. Medved \\ Laboratory for Sustainable Technology in Buildings, \\ Faculty of Mechanical Engineering, University of Ljubljana, Slovenia
}

\begin{abstract}
In this paper, methods and the development of computer tools for the comprehensive quality evaluation of the design and renovation of buildings are shown. Following the requirements of sustainable development and the Energy Performance of Buildings Directive (EPBD), an overall assessment is needed to estimate the quality of those processes. Such an assessment includes energy, environmental and costs optimisation in a life cycle period. Energy performance indicators are evaluated using EN standard procedures for the calculation of energy needs and final energy demand for EPBD building services operation. Environmental indicators are divided between mid-point characterisation, based on Environmental Product Declarations (EPD) and an end-point characterisation based on IMPACT 2002+ and ReCiPe methods. A discounted costs-and-savings cash flow method is used for cost optimal evaluation of the energy efficiency measures and renewable energy sources technologies. A case study of a hospital building is shown.

Keywords: nearly zero energy buildings, Energy Performance of Buildings Directive, computer tool, life cycle assessment.
\end{abstract}

\section{Introduction}

The Energy Performance of Building Directive (recast) [1] introduced targets for nearly zero energy buildings (nZEB) in the form of the allowed primary energy needed for operation of the building and the required amounts of energy supplied from on-site, nearby or distant technologies for the utilisation of renewable energy sources. In addition, it requires that all energy efficiency measures also be costeffective. The experts involved in building planning and renovation encounter this 
challenging task in the early stage of planning. In addition to the relevant multidisciplinary knowledge on life cycle assessment (LCA), a simplified computational tool to verify the decisions is needed to meet the requirements of EPBD.

Such a tool for energy, environmental, and cost life cycle assessment of new and renovated buildings is presented in this paper [2].

\section{Structure of the $E^{\text {tool }}$}

The aim of the life cycle assessment tool, named $E^{\text {tool }}$, is to enhance energy performance analysis with simultaneous environmental and costs assessment. In order to ensure wide use among designers of buildings, $\mathrm{E}^{\text {tool }}$ was developed as an upgrade of a computer tool for energy performance of buildings analysis that is widely used in the process of the energy labelling of buildings in Slovenia and consists of two computer codes: the building energy performance tool (BEPT), and the life cycle assessment tool (LCAT). BEPT enables the determination of energy needs for heating $\left(Q_{N H}\right)$ and cooling $\left(Q_{N C}\right)$ that are calculated according to EN13790 and that determination of final energy demand $\left(Q_{f}\right)$ for the operation of EPBD systems (heating, domestic hot water, cooling, ventilation, air-conditioning and lighting). Methods listed in the EN15316 group of standards are used for final energy demand analysis. The building energy performance tool includes upgraded computer routines to evaluate:

- Multiple determination of $Q_{N H}$ and $Q_{f}$ based on predefined influence parameters and their range of values;

- Inventory of energy carriers;

- Inventory of mid-point environment impact indicators of energy carriers and user-defined materials, appliances and systems;

- Yearly cost of energy carriers and proposed rational use of energy measures, and renewable energy technologies;

- Automatic data transfer to LCAT.

The life cycle assessment tool (LCAT) was developed in the way that enables:

- Classification of parameters that effect $Q_{N H}$ and $Q_{f}$;

- Creation of multi-parametric numerical models of $Q_{N H}$ and $Q_{f}$;

- Comparative energy (LCEA life cycle energy assessment), environment (LCIA life cycle impact assessment) and life cycle cost assessment (LCCA) of existing and renovated building.

\section{Methods for life cycle assessment}

\subsection{Life cycle energy assessment}

The analysis starts with a description of the building's envelope, indoor parameters, and EPBD systems in BEPT. This phase is similar to the energy 
performance indicator analysis that is in accordance with the national regulations and is, therefore, already well known to the building's designers.

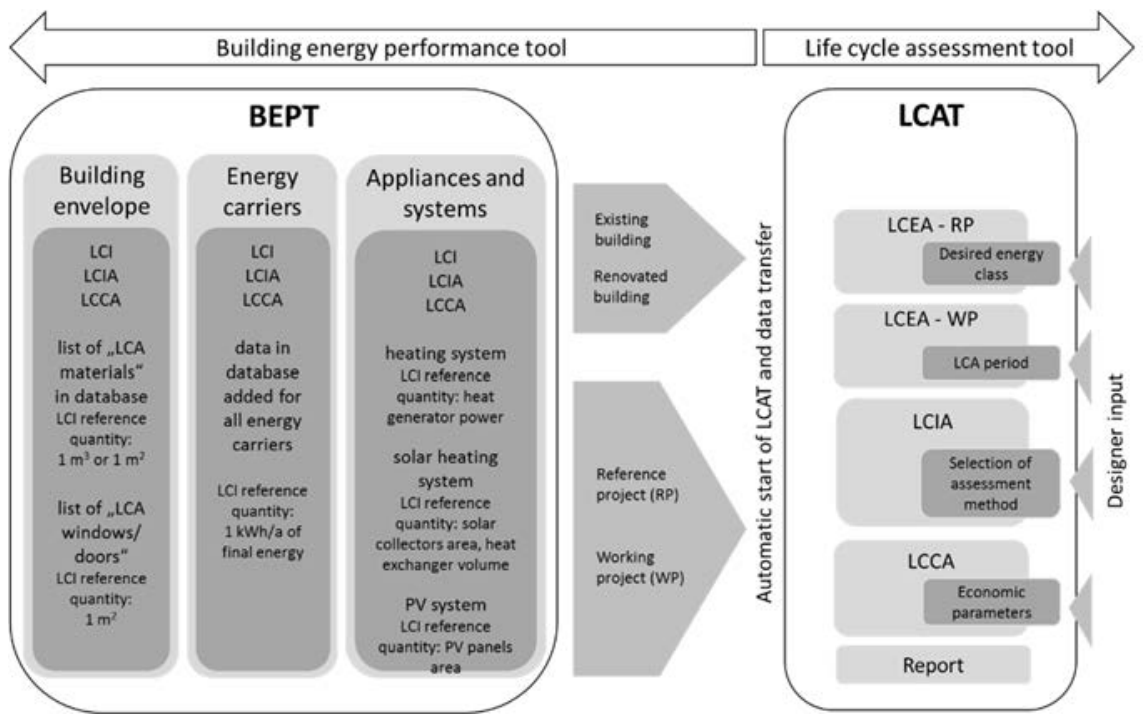

Figure 1: Graphic schematic of Etool structure and interactions between the building energy performance tool (BEPT) and life cycle assessment tool (LCAT).

For classification of influence parameters, the calculation loop for the determination of the energy need for heating $Q_{N H}$ and final energy demand for operation of the building, $Q_{f}$ runs in the background of the computational process. This process is based on preselected numbers and values of parameters that influence $Q_{N H}$. These parameters are divided into two groups: a) construction parameters (including thermal transmittances of walls, roofs, floors, and windows, thermal bridge coefficient, solar transmittance of glass, airtightness of the building, and temperature efficiency of heat recovery units) and b) residentinfluenced parameters (including operative temperature, ventilation air exchange rate and internal heat gains). For each of the influence parameters, two sets of five values were selected: one for new buildings and another one for refurbished buildings. The parameter values for new buildings were in the range of between passive house standards and national regulations. Meanwhile, the parameter values for refurbished buildings were selected according to the observation of existing building funds. In the case of final energy demand, $Q_{f}$ parametrisation, three parameters were added (energy need for domestic hot water, solar collector area, and heat storage volume). In this case only three levels were selected for each parameter. To minimise the number of numerical simulations, the combination of parameter values were determined with Taguchi orthogonal array, which was selected based on the degree-of-freedom number, which is defined by numbers of levels and influence parameters [3]. In our case, the Taguchi orthogonal array L50 
was used for $Q_{N H}$ and L27 for $Q_{f}$ parametrisation. Such an approach reduces the number of numerical experiments needed to 50 or 27. After completing the calculation loop, the Taguchi method is used to define the rank of influential parameters. A signal-to-noise approach and "minimum is better" criteria were used for ranking the parameters. The percentage of contribution is calculated by implementing the ANOVA method. This enables building designers to implement the most efficient measures of energy efficiency for the analysed building. After completing calculations in BEPT, the data are automatically transferred to LCAT, where the data are further analysed and presented to the user. LCAT was developed in MS Excel. Using Excel's Linest function, the multi-parametric approximation models of $Q_{N H}$ and $Q_{f}$ are developed to enable the designer to adjust the values of basic construction parameters to in-situ conditions. Eqn (1) shows a model for specific energy needs for heating that is used for parametrisation; Figure 2 shows a user interface that enables the adjustment of the parameters' values and the instant value of $Q^{\prime}{ }_{N H}$,mod.

$$
Q_{N H, \text { mod }}^{\prime}=b_{0}+\sum_{i=1}^{n}\left(b_{1, i} \times k_{i}+b_{2, i} \times k_{i}^{2}+b_{3, i} \times k_{i}^{3}\right) \frac{\mathrm{kWh}}{\mathrm{m}^{2} \mathrm{a}} .
$$

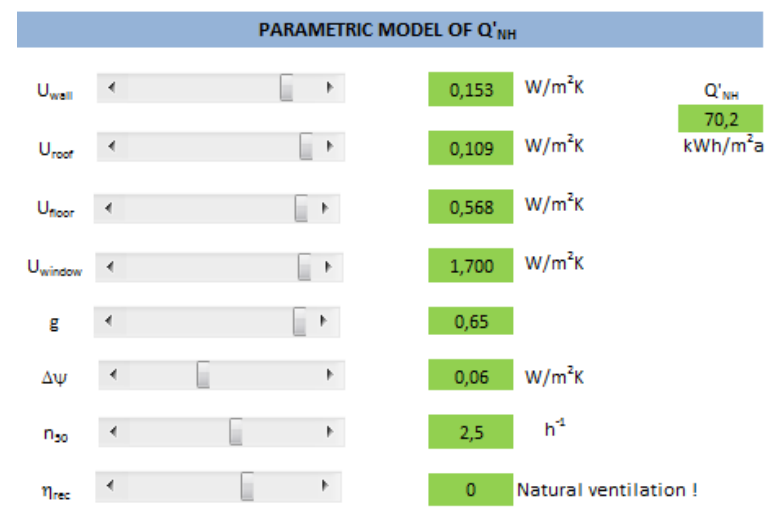

Figure 2: User interface in LCAT, which enables users to adjust basic construction parameters

In eqn (1), $Q{ }^{\prime}{ }_{N, \text { mod }}$ represents modelled specific energy needed for heating, $k_{i}$ construction parameters, $b_{0}, b_{1, i}, b_{2, i}, b_{3, i}$ coefficients of multi-parametric approximation models, and $n$ number of parameters. A similar approach is used for the determination $Q_{f}$.

The results of multi-parametric analyses are presented graphically for the existing and renovated building to enable the designer to evaluate the effectiveness of the proposed energy efficiency measures. Other presented energy performance indicators include a comparison of energy carriers' inventories, the primary energy needed for building operation, $\mathrm{CO}_{2}$ emissions and global warming potential, the share of renewable energy sources, and the embodied energy of energy 
conservation measures and fuels in the LCA period that is defined by the designer. The user interface of the life cycle energy assessment (LCEA) module is presented in Figure 3.

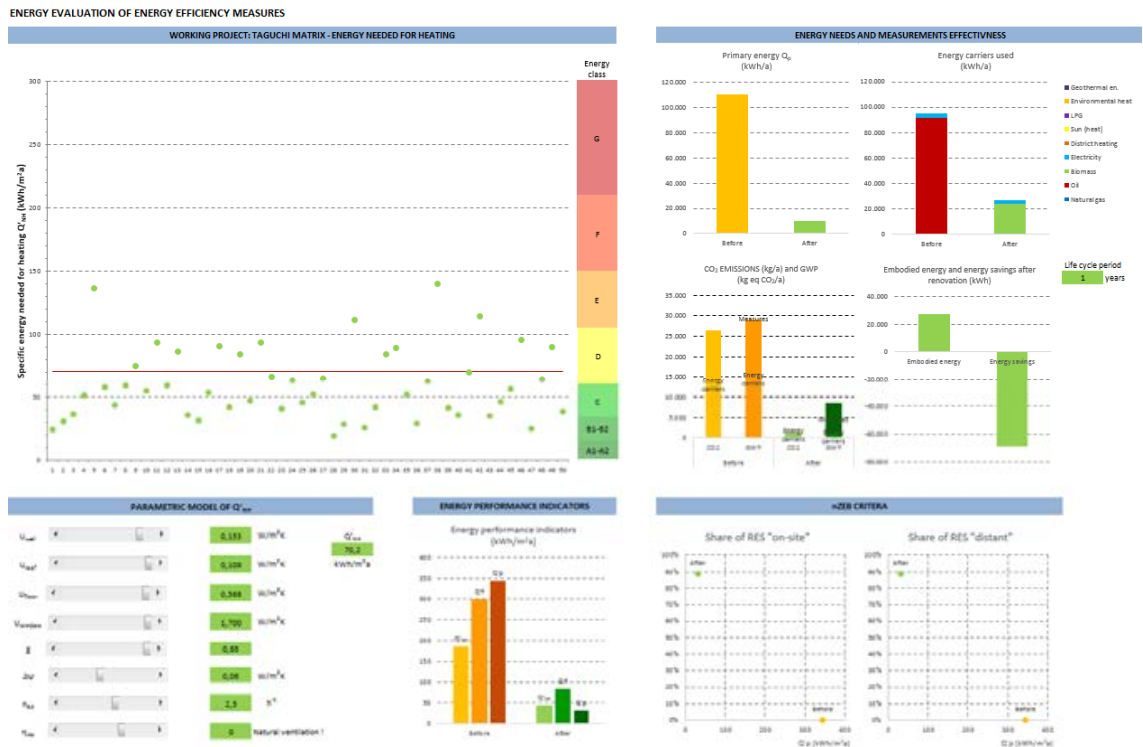

Figure 3: User interface of LCEA module in $\mathrm{E}^{\text {tool }}$.

\subsection{Life cycle impact assessment}

For the purpose of an environment impact assessment, the life cycle inventory database is integrated into the BEPT. The life cycle inventory database includes data on predefined building materials, envelope components (windows and doors), heat generators, and energy carriers. Environmental impact assessment is performed only for user-selected materials or components from this database. An overview of life cycle inventory databases showed that Environmental Product Declarations (EPD) are most convenient while there are many open source databases for building materials and systems (i.e. Ökobaudat, Eco Platform). Among the included environmental indicators, those with the most significant impact on human health and global climate change were selected: global warming potential (GWP), ozone depletion potential (ODP), acidification potential (AP), eutrophication potential (EP), photochemical ozone creation potential (POCP), abiotic depletion potential - elements (ADPE), and abiotic depletion potential fossil fuels (ADPF). All indicators are presented in equivalents of reference substances. According to common available EPDs, modules from A1 to A3 (product stage - raw material supply, transport, manufacturing) are included in the LCA analysis. The values of environmental indicators are approximated with different models and reference values: 
- for the "LCA" materials, a linear approximation model is used with area or volume as reference quantities,

- for the "LCA" windows and doors, an approximation model that includes window area, the share of glazing and frame thickness as reference variables is used,

- for "LCA" heat generators, a quadratic approximation model is used with nominal heating power as a reference value,

- for the solar thermal collectors and PV systems, a linear approximation model is used with the area as a reference value,

- for heat storage, a quadratic approximation model is used with volume as a reference value, and

- for energy carriers, a linear approximation model is used with $\mathrm{kWh}$ as a reference quantity.

Emissions of equivalents of environmental indicators are calculated in BEPT, and data are transferred to the LCIA module of LCAT, where mid-point characterisation is done (Figure 4).

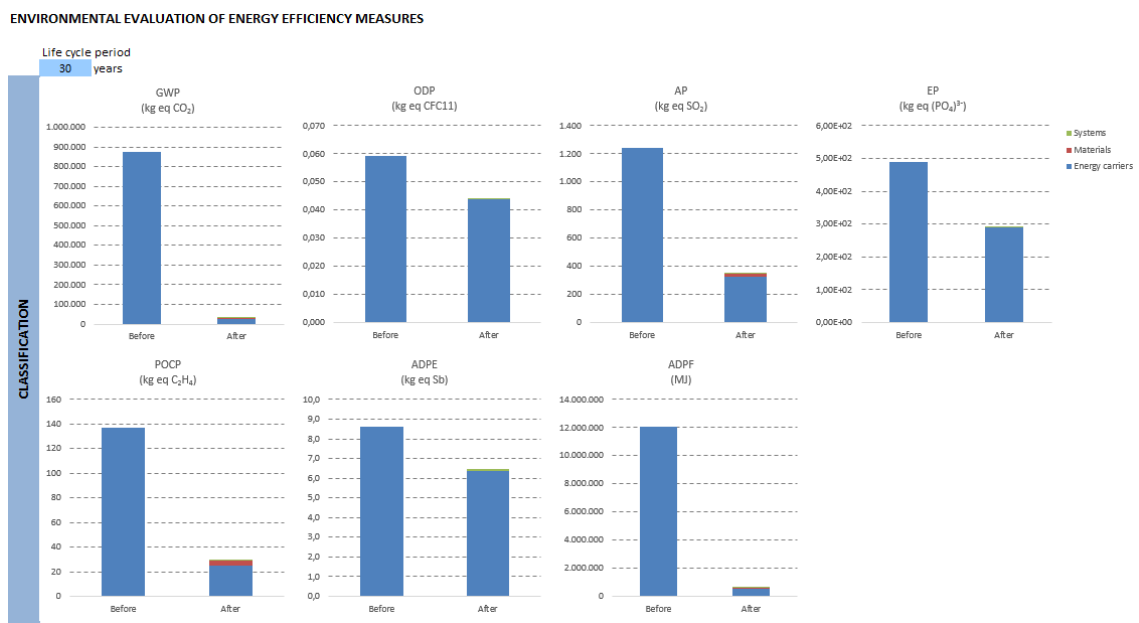

Figure 4: Mid-point characterisation of environmental impact of reference and working project in $\mathrm{E}^{\text {tool }}$.

End-point characterisation is done using IMPACT 2002+ [4, 5] and methods [6]. In the first case, the damage categories are climate change, human health, ecosystems quality, and resources; in the ReCiPe method, only three damage categories (human health, ecosystems quality, and resources) are analysed (Figure $5)$.

In the last stage of LCIA, the total environmental impact is determined as the sum of partial contributions of each damage category. This leads to the single environmental impact indicator in the form of points per year. This step is introducing normalisation factors for each damage category. In $\mathrm{E}^{\text {tool }}$, the values of 
normalisation factors were determined, taking into account total EU emissions and number of inhabitants $\left(43110^{6}\right)$.

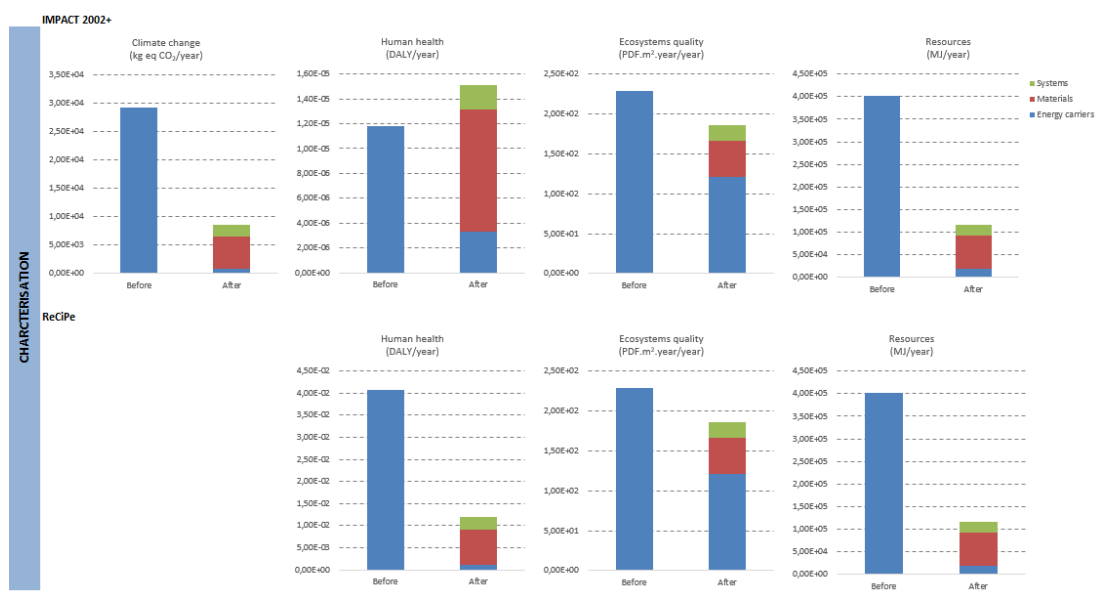

Figure 5: End-point characterisation of damage categories of the reference and working project in $\mathrm{E}^{\mathrm{tool}}$.

\subsection{Life cycle costs assessment}

The life cycle costs assessment module was developed according to Commission Delegated Regulation No. 244/212 [7]. This document defines the method for the evaluation of costs optimal values of energy efficiency measures for nearly zero energy buildings (nZEB). Within this method, discounting costs and savings cash flows in a preselected period are determined. The LCCA module in $\mathrm{E}^{\text {tool }}$ enables calculation of year-by-year cash flows using eqn (2).

$$
L C C_{n}=\sum_{i=0}^{n}\left[\left(c_{u}+c_{a}\right)_{i} \cdot(1+d)^{i}+\sum_{l=1}^{m} P_{e, l} \cdot \frac{\left(1+e_{l}\right)^{i}}{(1+d)^{i}}\right]-V(n) \quad \text { EUR }
$$

In eqn (2), $L C C_{n}$ represents life cycle costs after $n$ years, $c_{u}$ investment costs, $c_{a}$ maintenance costs, $P_{e}$ energy carrier savings, $d$ discount factor, $e$ discount factor of energy carrier prices, and $m$ number of energy carriers needed for building operation. The discount factor and the prediction of energy prices strongly influence the determination of the cost-effectiveness of measures. For the macroeconomic analysis of the sensitivity analysis, an annual discount factor of 3 percent is taken into account according to the Commission Delegated Regulation [7]. Predicted energy prices are taken from the Guidelines accompanying Commission Delegated Regulation No. 244/212 [8]. Remaining values of energy efficiency measures $V(n)$ at the end of the calculation period is calculated 
regarding life cycle period are determined regarding the Guidelines [8] as well as the macroeconomic costs caused by emissions of a $\mathrm{CO}_{2}$ equivalent.

Investment costs of energy efficiency measures are calculated in BEPT by parametric models, which are designed similar to parametric models of environmental indicators, presented in Section 3.2, and are transferred to the LCCA module of LCAT for further analyses and presentation of results. In Figure 6 , the user interface of the LCCA module is presented. Discounted cash flow, the structure of life cycle costs, specific total costs of energy efficiency measures and energy carriers in $n$ years, and primary energy demand per $\mathrm{m}^{2}$ of conditioned area of the building, and macroeconomic costs of eqCO $\mathrm{CO}_{2}$ emissions are shown.

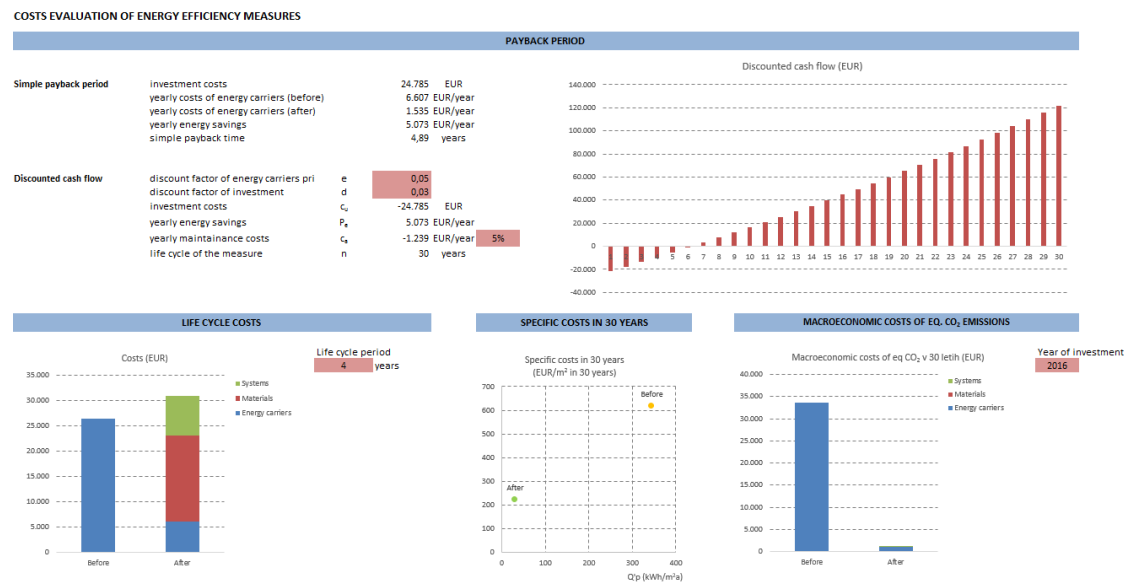

Figure 6: User interface of LCCA module in $\mathrm{E}^{\text {tool }}$.

\section{Case study}

For the purpose the case study, the overall analysis of a hospital building renovation was performed. The hospital conditioned area of $7405 \mathrm{~m}^{2}$ is presented in Figure 7. A district heating system is used for heating and DHW, naturally ventilated (except the microbiological laboratory with $1 / 10$ of total volume, which is mechanically ventilated with a heat recovery unit), compact and tube fluorescent lamps are used for lighting with installed capacity $4.4 \mathrm{~W} / \mathrm{m}^{2}, U$ value of walls is $1.3 \mathrm{~W} / \mathrm{m}^{2} \mathrm{~K}, U$ value of ceiling towards the unheated attic is $0.957 \mathrm{~W} / \mathrm{m}^{2} \mathrm{~K}$ and $U$ value of windows and doors is $3.0 \mathrm{~W} / \mathrm{m}^{2} \mathrm{~K}$.

\section{Step 1}

The classification of influence parameters is presented in Figure 8. It can be seen that the indoor temperature is the most influential parameter, which leads to the conclusion that installing thermostatic valves, the hydraulic balance of pipelines, and installing advanced controlled units are the most important measures. While the air exchange rate is an important parameter as well, the replacement of the windows (with a classification value of 26 percent) will effectively contribute to 
lowering the energy needed for heating because of the air tightness of the new windows. The $g$ value of new windows must be selected carefully because the classification of the influence of this parameter is comparable with thermal insulation of the ceiling. Thermal insulation of the walls can also be justified.

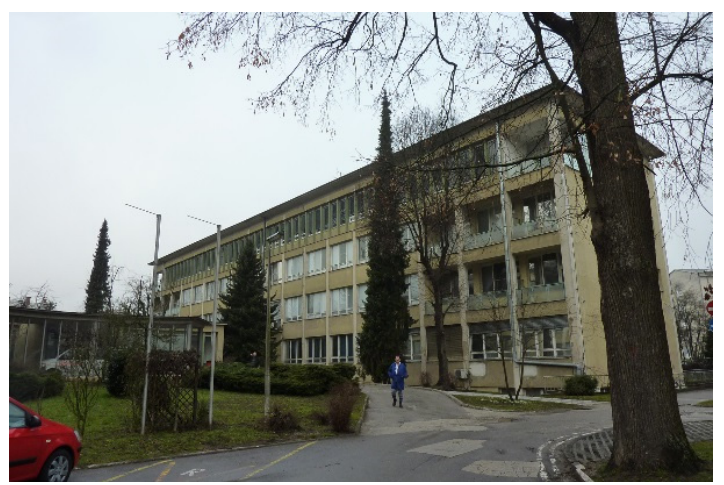

Figure 7: Case study hospital building.

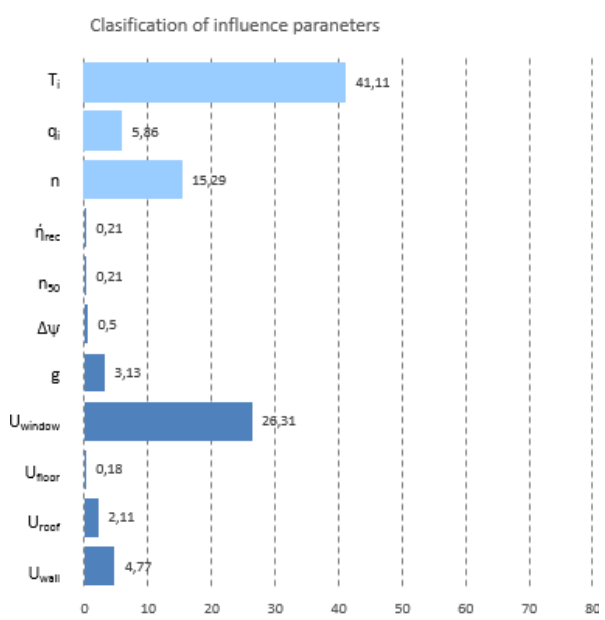

Figure 8: The classification of influence parameters.

\section{Step 2}

Proposed measures: replacement of windows with $U$ value $1.1 \mathrm{~W} / \mathrm{m}^{2} \mathrm{~K}$ and g value 0.55 , installation of $18 \mathrm{~cm}$ thick thermal insulation on walls $\left(\mathrm{U}_{\text {wall }}=0.168\right.$ $\mathrm{W} / \mathrm{m}^{2} \mathrm{~K}$ ), installation of $30 \mathrm{~cm}$ thick thermal insulation on the ceiling towards unheated attic $\left(U_{\text {roof }}=0.096 \mathrm{~W} / \mathrm{m}^{2} \mathrm{~K}\right)$, and installation of thermostatic valves on end heat exchangers. These measures result in 72 percent lower energy needed for heating $\left(Q{ }^{\prime}{ }_{\mathrm{NH}} 152 \mathrm{kWh} / \mathrm{m} 2 \mathrm{a} \rightarrow 42 \mathrm{kWh} / \mathrm{m}^{2} \mathrm{a}\right)$, in 68 percent lower final energy demand $\left(Q^{\prime}{ }_{\mathrm{f}} 220 \mathrm{kWh} / \mathrm{m}^{2} \mathrm{a} \rightarrow 70 \mathrm{kWh} / \mathrm{m}^{2} \mathrm{a}\right.$ ) and in 58 percent lower primary 
energy demand ( $Q_{\mathrm{p}}$ $\left.250 \mathrm{kWh} / \mathrm{m}^{2} \mathrm{a} \rightarrow 105 \mathrm{kWh} / \mathrm{m}^{2} \mathrm{a}\right)$. Eligibility of measures can also be checked by embodied energy. As can be seen, the "energy return rate" of embodied energy is less than one year (see Figure 9).

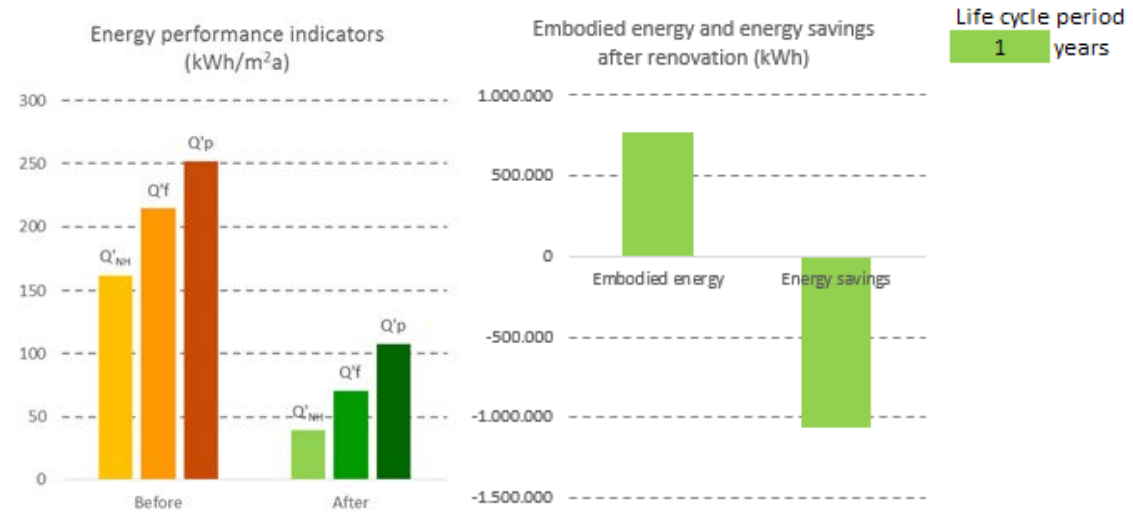

Figure 9: Energy performance indicators and embodied energy.

\section{Step 3}

As a result of lower emissions of pollutants and decreased use of natural resources, the Eco Points also decrease, from $68 \mathrm{Pt} /$ year to $59 \mathrm{Pt} / \mathrm{year}$ in the first year after renovation and to $24 \mathrm{Pt} / \mathrm{year}$ in each following year. The implemented energy efficiency measures cause $35 \mathrm{Pt} / \mathrm{year}$, but only in the year of renovation. Obviously, the renovation has significant environmental benefits (see Figure 10).

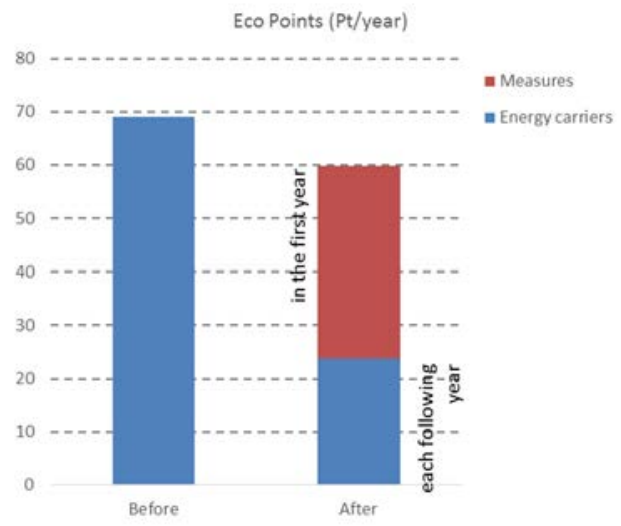

Figure 10: Eco points.

\section{Step 4}

From the discounted cash flow diagram, it can be seen that the costs of measures will be approximately 720,000 EUR and the payback period 16.8 years. The 
specific costs of operation of building's services system in a 30-year life cycle period will be reduced from $398 \mathrm{EUR} / \mathrm{m}^{2}$ to $295 \mathrm{EUR} / \mathrm{m}^{2}$ of conditioned area, which also proves that measures are cost effective. From the microeconomic perspective, the expenses regarding emissions of $\mathrm{CO}_{2}$ equivalent will be reduced by 321,000 EUR in 30 years of operation of the building. This indicates that any investment from the state in energy efficiency measures to this value can be justified (see Figure 11).
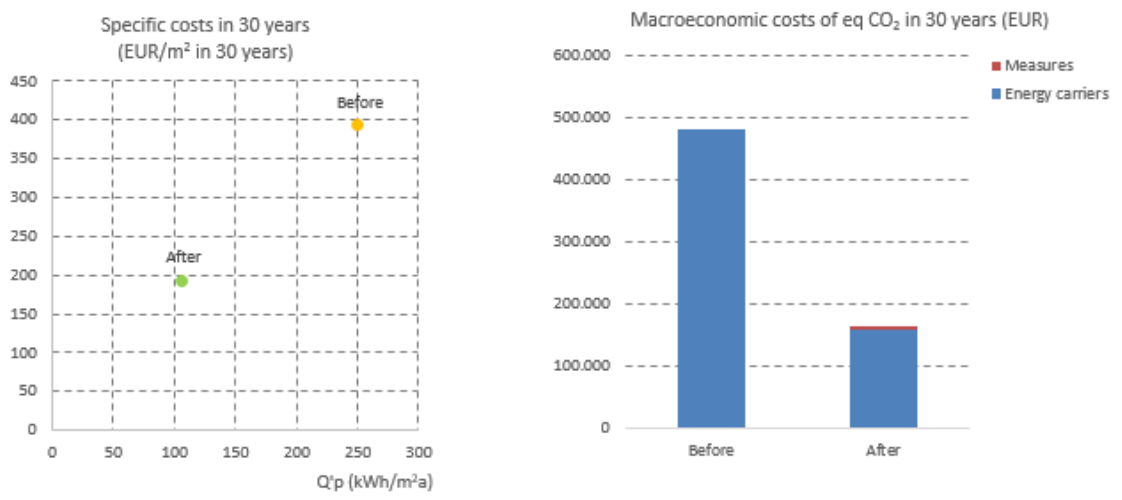

Figure 11: Specific and macroeconomic costs in 30 years.

\section{Conclusions}

The main goal of the authors of the $E^{\text {tool }}$ computer tool was to contribute to overcoming two main obstacles in design of new buildings and renovation processes: the complexity of methods for overall assessment (energy, environmental, and costs analyses) and the fact that despite the existence of a number of computer tools there is a lack of a simplified all-in-one computer tool.

To enable the wide use of the developed tool, the database of energy, environment and costs data on materials, appliances and energy carriers are open to the user, which allows adaptation to specific local or national conditions.

\section{References}

[1] Directive 2010/31/EU of the European Parliament and of the Council of 19 May 2010 on the energy performance of buildings (recast), 2010.

[2] Domjan, S., Parametric models for multi-criteria analysis of nearly zeroenergy buildings. Master's thesis, University of Ljubljana, Faculty of Mechanical Engineering, 2016.

[3] Fraley, S., Oom, M., Terrien, B. \& Zalewski, J., Design of experiments via Taguchi methods: Orthogonal arrays. University of Michigan, 2006.

[4] Humbert, S. et al., IMPACT 2002+: User Guide, Life Cycle Assessment Expert, Quantis: Lausanne, 2012. 
188 Global Dwelling: Approaches to Sustainability, Design and Participation

[5] Humbert, S. et al., IMPACT 2002+ vQ2.22: Characterization factors, Life Cycle Assessment Expert, Quantis: Lausanne, 2014.

[6] Goedkoop M. et al., ReCiPe 2008: A life cycle impact assessment method which comprises harmonised category indicators at the midpoint and the endpoint level, 1st ed. Ministrie van Volkshuisvesting, Ruimtelijke Ordening en Milieubeheeer (Ministry of VROM), 2009.

[7] Commission Delegated Regulation (EU) No. 244/2012.

[8] Guidelines Accompanying Commission Delegated Regulation (EU) No. 244/2012. 